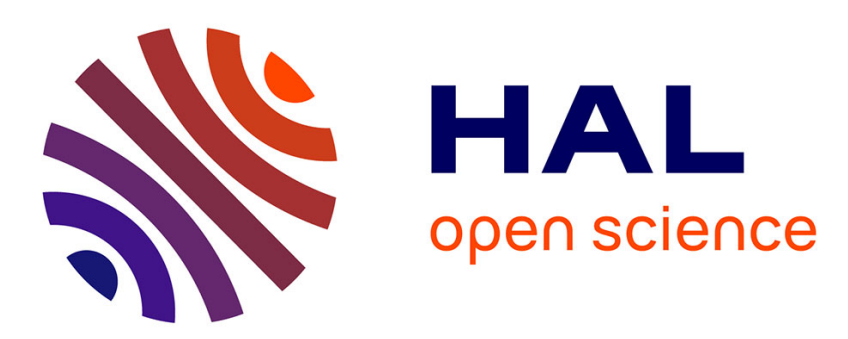

\title{
H.R.E.M. observation of thermally induced $\epsilon$-martensite plates in a Fe-Mn-Si-Cr-Ni shape memory alloy
}

\author{
J. Putaux, L. Federzoni, M. Mantel, G. Blanc, Jérome Chevalier
}

\section{To cite this version:}

J. Putaux, L. Federzoni, M. Mantel, G. Blanc, Jérome Chevalier. H.R.E.M. observation of thermally induced $\epsilon$-martensite plates in a Fe-Mn-Si-Cr-Ni shape memory alloy. Journal de Physique IV Proceedings, 1993, 03 (C7), pp.C7-545-C7-548. 10.1051/jp4:1993789 . jpa-00252209

\section{HAL Id: jpa-00252209 https://hal.science/jpa-00252209}

Submitted on 1 Jan 1993

HAL is a multi-disciplinary open access archive for the deposit and dissemination of scientific research documents, whether they are published or not. The documents may come from teaching and research institutions in France or abroad, or from public or private research centers.
L'archive ouverte pluridisciplinaire HAL, est destinée au dépôt et à la diffusion de documents scientifiques de niveau recherche, publiés ou non, émanant des établissements d'enseignement et de recherche français ou étrangers, des laboratoires publics ou privés. 


\title{
H.R.E.M. observation of thermally induced $\varepsilon$-martensite plates in a Fe-Mn-Si-Cr-Ni shape memory alloy
}

\author{
J.L. PUTAUX, L. FEDERZONI ${ }^{*}$, M. MANTEL ${ }^{* *}$, G. BLANC ${ }^{* *}$ and J.P. CHEVALIER \\ Centre d'Etudes de Chimie Métallurgique, CNRS, 15 rue G. Urbain, 94407 Vitry cedex, France \\ * GEMPPM, Bât. 502, INSA, 69621 Villeurbanne cedex, France \\ *** Centre de Recherche d'Ugine, Ugine Savoie, 73403 Ugine cedex, France
}

\begin{abstract}
RESUME: Des échantillons polycristallins d'un alliage $\mathrm{Fe}-\mathrm{Mn}-\mathrm{Si}-\mathrm{Cr}-\mathrm{Ni}$ à mémoire de forme, contenant $70 \%$ de martensite $\varepsilon$ thermique, ont été étudiés par M.E.H.R. Les images mettent en évidence, à l'échelle atomique, la structure feuilletée de la phase $\varepsilon$. En analysant des images traitées numériquement de l'extrémité de plaquettes $\varepsilon$ élémentaires, l'interface $\varepsilon / \gamma$ a été décrite au moyen d'une distribution périodique de partielles de Shockley à $30^{\circ}$ et $90^{\circ}$ dans le rapport $2 / 1$, ce qui traduit les propriétés d'auto-accommodation de la martensite $\varepsilon$ thermique à l'échelle la plus fine.
\end{abstract}

\begin{abstract}
Polycrystalline samples of a Fe-Mn-Si-Cr-Ni shape memory alloy containing a $70 \%$ fraction of thermal $\varepsilon$-martensite have been studied by H.R.E.M. Images taken along a $\langle 011>\gamma / /<2110\rangle \varepsilon$ axis clearly show, at the atomic level, the layered substructure of larger $\varepsilon$-bands. By analysing numerically processed images of elementary $\varepsilon$-laminate tips, the $\varepsilon / \gamma$ interface could be described by a periodic array of $30^{\circ}$ and $90^{\circ}$ Shockley partials in a 2:1 ratio, leading to self-accommodation of thermal $\varepsilon$-martensite at the finest scale.
\end{abstract}

\section{INTRODUCTION}

Using high resolution electron microscopy (HREM), we have observed polycrystalline samples of a shape memory alloy made by Ugine Savoie, with a composition of Fe $-15.9 \mathrm{Mn}-5 \mathrm{Si}-9.1 \mathrm{Cr}-4.2 \mathrm{Ni}$ (in weight\%). This alloy exhibits a martensitic transformation from face centred cubic $\gamma$-austenite to close packed hexagonal $\varepsilon$-martensite. This transformation has already been investigated in $\mathrm{FeMnSiCrNi}$ alloys using electron microscopy and in situ techniques $[1,2,3]$. We focused our study on thermal $\varepsilon$-martensite (as opposed to the deformation martensite), formed by cooling under the $\mathbf{M}_{\mathbf{s}}$ temperature.

\section{EXPERIMENTALS}

Federzoni et al [4] recently proposed a thermomechanical treatment that produced an maximum quantity of thermal martensite in an alloy obtained by a usual casting method. This treatment is:

- step 1: cold rolling $+850^{\circ} \mathrm{C}$ annealing $(30 \mathrm{mn}$, air) + slow cooling

- step 2: 7\% deformation $+800^{\circ} \mathrm{C}$ annealing $(5 \mathrm{mn}$, air $)+$ quenching in liquid $\mathrm{N}_{2}$

After step 1, the material contained $4 \%$ of thermal $\varepsilon$ phase. After step 2, the thermally induced fraction of $\varepsilon$ martensite increased to $70 \%$. Electron microscopy samples were electrolytically thinned and observed using a Topcon ABT $002 \mathrm{~B}$ ultra high resolution microscope operating at $200 \mathrm{kV}$.

\section{OBSERVATIONS AND RESULTS}

We have more particularly observed a configuration corresponding to the interaction between a large $\varepsilon$ plate and an austenite microtwin. On the high resolution micrograph of figure 1 , one can clearly see, at an atomic 


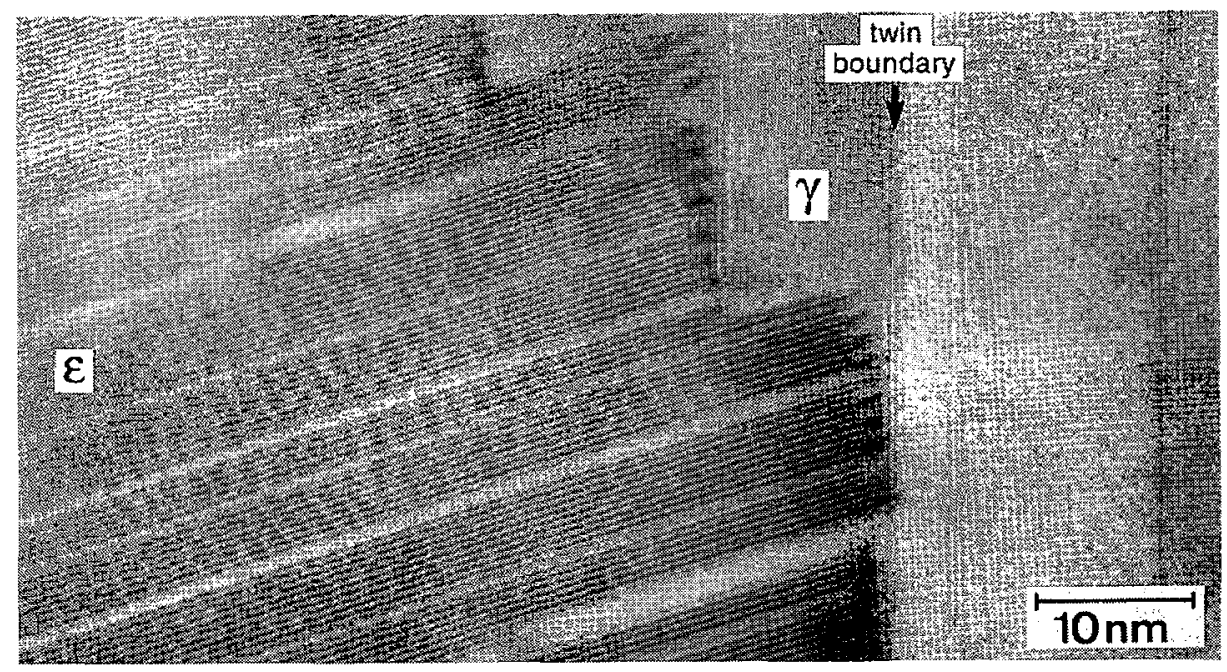

Fig.1. High resolution micrograph of the zone of interaction between the $\varepsilon$ phase and an austenite microtwin. The cristal is oriented along $a<011>\gamma / /<2110>\varepsilon$ axis common to both phases.

scale, the substructure of the plate. Both $\varepsilon$ and $\gamma$ phase are observed and very thin individual $\varepsilon$-laminates can be seen. From the overall morphology, it is clear that the austenite that is around the laminates is not trapped inside the $\varepsilon$-martensite but instead that the $\varepsilon$ phase has grown into the $\gamma$-matrix. As already observed by Yang et al [3], the plates of thermal $\varepsilon$ martensite exhibits a layered structure.

The $\varepsilon$ laminates appear to be blocked by the microtwin. The $\varepsilon / \gamma$ interface at a laminate tip, which generally lies perpendicular to its long axis, shows small periodic dark patches giving it a comb-like appearance. Due to the important thickness of the observed zone and to an amorphous organic contamination layer on the specimen surface, the images are very noisy. Thus, it has proved necessary to filter them numerically to reduce noise and enhance contrast. We used a mask which allowed the spatial frequencies corresponding to the diffracted spots (with the exception of the (0001) $\varepsilon$ forbidden spots), as well as the streaks, to form the reconstructed image (fig. 2c). On the other hand, HREM image simulation was used to determine that, for this range of thickness, the atoms were likely to appear as white dots. This image treatment performed on the high resolution micrograph showed that the periodic dark patches were due to small intrinsic stacking faults emerging from the interface over a few interatomic distances (fig. 2a and $2 \mathrm{c})$. The periodicity of these stacking faults corresponds to $6 \times(111) \gamma / /(0002) \varepsilon$ atomic planes .

In order to analyse the dislocation content of the $\varepsilon / \gamma$ interface, one has to keep in mind that, for HREM imaging along [101], only dislocations whose lines are parallel to this can be analysed. 3 such dislocations can transform an f.c.c. into an h.c.p. crystal: two $30^{\circ}$ Shockley partials (with opposite screw components) and one $90^{\circ}$ partial (with an edge component opposite to the $30^{\circ} \mathrm{s}$ ). The sum of all three Burgers vectors is zero. Along the [101] direction, only edge components can be detected, thus giving the impression of having only two types of Shockley partials: $\mathbf{b}_{90}$ and $-\mathbf{b}_{30} \pm .30^{\circ}$ partials cannot be discriminated and the " $\pm "$ sign is here as a reminder of the uncertainty on the sign of their screw components.

Supposing that the interface contained only Shockley partials, we have used the method described by Howe et al [8] to analyse the dislocation content of the interface. These authors have defined two circuits that discriminate between $30^{\circ}$ and $90^{\circ}$ partials. This method applied to a numerically processed image gives the result shown in fig. 3. Circuit 1 leads to a closure failure equivalent to $10 \times 30^{\circ}$ Shockley dislocations and circuit 2 , to $5 \times 90^{\circ}$ ones. Thus, for a portion of interface 30 plane wide, we find that the proportion is: $n\left(-b_{30} \pm\right) / n\left(b_{90}\right)=2 / 1$. 

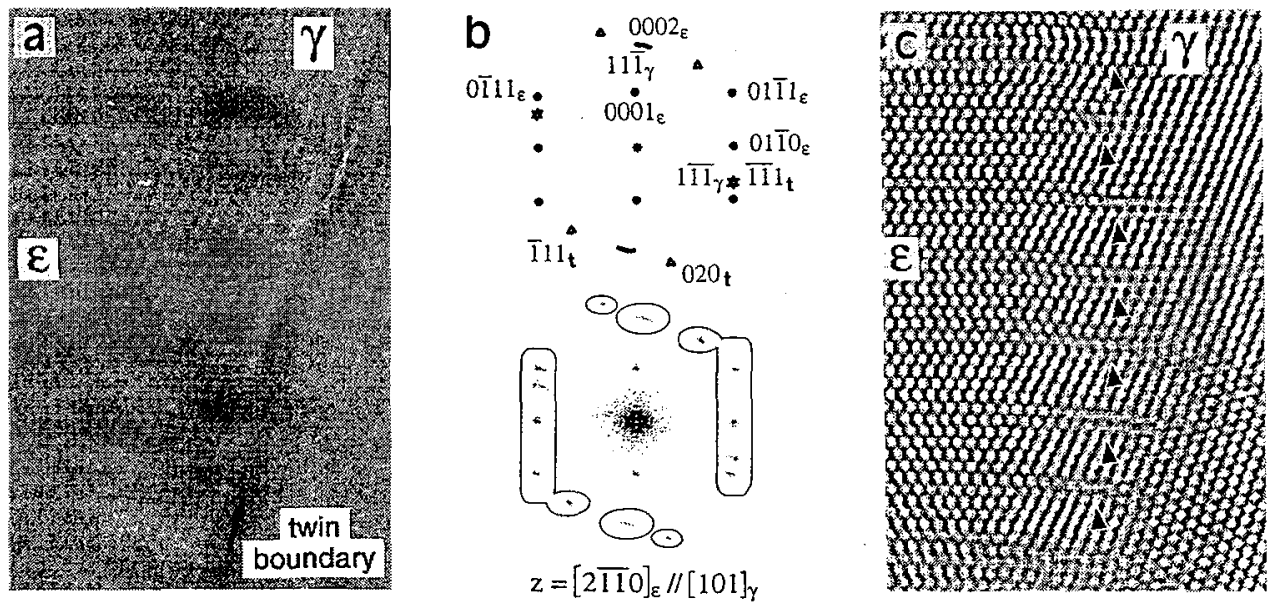

Fig.2. a) H.R.E.M. Image of the $\varepsilon / \gamma$ interface at a laminate tip, close to the twin ( $t$ ) boundary.

b) Power spectrum of image $a$ : above, the spots are identified with respect to the corresponding diffracting plane family; below are drawn the masks used for the numerical processing.

c) Image $a$ after processing. The arrows indicate the small stacking faults emerging from the interface.

A distribution of $30^{\circ}$ partials of the same type would introduce an important twist component in the interface. For this reason, we think that both types of $30^{\circ}$ partials are probably in equal number to cancel out the effects of their opposite screw components. The Shockley proportion is finally found to be $n\left(-b_{30}{ }^{+}\right)=n\left(-b_{30}{ }^{-}\right)=n\left(b_{90}\right)$. Thus, the global Burgers vector around this portion of interface is zero.

\section{DISCUSSION}

Mixed types of Shockley are found in the $\varepsilon / \gamma$ interface. Therefore, the laminate growth is not achieved by the multiplication of only one type of partial from poles such as suggested by Seeger [6]. Moreover, for the thermal $\varepsilon$-martensite studied here, since the dislocations are periodically distributed, we can exclude a random nucleation mechanism and a process of progressive stacking fault pile-up [7] [2].

The periodic distribution of the dislocations implies a strong short range correlation of the Shockley partials that nucleate and glide every other plane. Thus, the elastic energy associated with the phase transformation

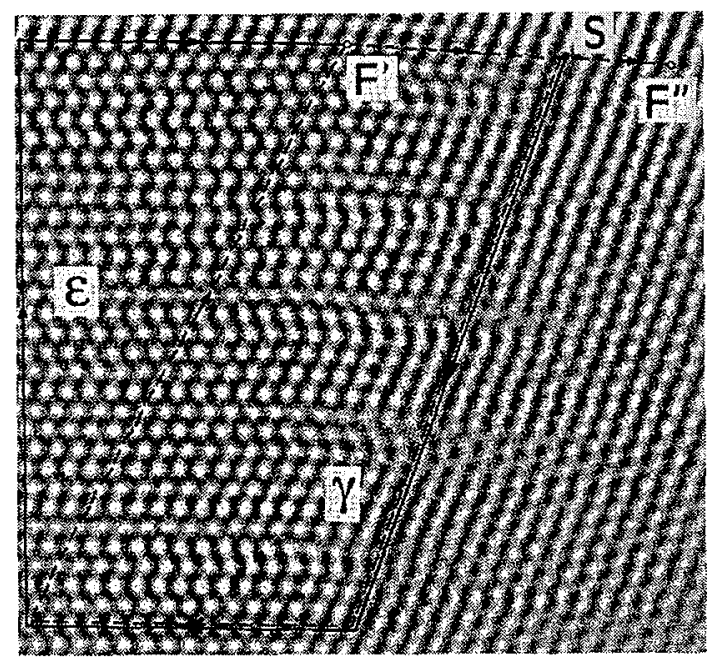

Fig.3. Determination of the $30^{\circ}$ and $90^{\circ}$ Shockley partial proportion in the $\varepsilon /$ yinterface by the method of Howe et al [8]:

$$
\begin{gathered}
\overrightarrow{S F}^{\prime} \Rightarrow 10 \times\left(\vec{b}_{30}^{ \pm}\right) \\
\overrightarrow{S F^{\prime \prime}} \Rightarrow 5 \times\left(\vec{b}_{90}\right)
\end{gathered}
$$


Fig.4. Schematic representation of the transformation of an f.c.c. crystal in h.c.p. martensite:

a) preferential variant growth by deformation;

b) spontaneous transformation self-accommodated by alternating 3 shears (after [5]).

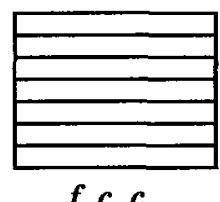

$f . c . c$.

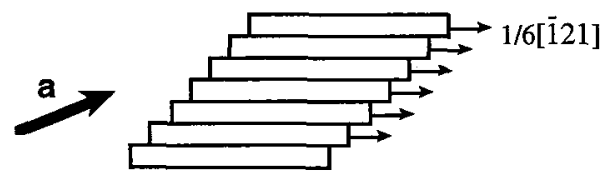

$\boldsymbol{h} . \boldsymbol{c} \cdot \boldsymbol{p}$.
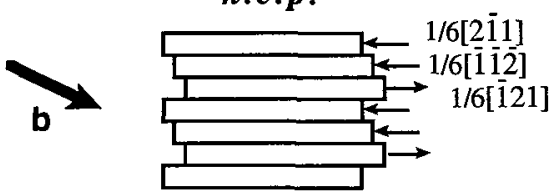

is minimised and the deformation is globally zero at the finest scale. The austenite is likely to transform by propagation of thin $\varepsilon$-laminates bounded by a few correlated Shockley partials. Since the glide on the $\{111\} \gamma$ planes is very fast, lateral growth is difficult and the martensite densification is achieved by the nucleation of new elementary laminates. This agrees with the scale of the observed layered substructure.

The laminate thickness has to stay limited to prevent the development of sessile Frank partials. These dislocations might form to accommodate the misfit between the $\varepsilon$ and $\gamma$ phases but their movement by climb on $\{111\} \gamma$ planes would require diffusion. That we did not observe such defects is an important result regarding the shape memory properties of the alloy.

Figure 4 recalls schematically two ways of transforming a f.c.c. crystal into h.c.p. martensite. When the transformation is spontaneous (fig. 4b), a global zero deformation is obtained by alternating the shears associated with each Shockley propagation. Studying an alloy with a composition close to ours, Yang et al [5] observed that, in large $\varepsilon$-bands, the thickness of one elementary block, formed by several partials of the same type, could reach a few $\mathrm{nm}$. In our case, we have seen that $\varepsilon$-martensite was self-accommodated at the dislocation scale. Thus, one block corresponds to only two planes sheared by one Shockley partial. Since self-accommodation is sensitive to local stresses, depending on the distribution of these stresses, the nature and proportion of the transformation dislocations will vary. That we observed self-accommodation at the finest scale means that the residual stresses in our recrystallised alloy, before quenching, are extremely low.

\section{CONCLUSION}

The layered substructure of thermal $\varepsilon$-martensite plates has been confirmed at the atomic level by HREM. Even though we did not get informations about the nucleation mechanism of the $\varepsilon$ phase, we propose that the transformation occurs by the propagation of elementary $\varepsilon$-laminates a few atomic planes thick. These laminates grow by the correlated glide of 3 types of Shockley partials, in equal proportion and periodically distributed in order to compensate the alternating shears. Thus, the deformations are self-accommodated at the finest scale. $\varepsilon$-phase densification is then achieved by nucleation of new thin laminates rather than by thickening of those already formed. These results readily explain an easy reversion of the $\varepsilon$ phase.

\section{REFERENCES:}

[1] INAGAKI H., Z. Metallkd. 83-2 (1992) 90, 97.

[2] INAGAKI H., Z. Metallkd. 83-5 (1992) 304.

[3] YANG J.H., CHEN H., WAYMAN C.M., Metall. Trans. 23A (1992) 1431, 1439, 1445.

[4] FEDERZONI L., GEX D., GU Q., GUENIN G., LABROSSE D., MANTEL M., VAN HUMBEECK J., ICOMAT 92 , Monterey (USA).

[5] YANG J.H., WAYMAN C.M., Mater. Charact. 28 (1992) 23, 37.

[6] SEEGER A., Z. Metallkd. 47 (1956) 653.

[7] FUJITA H., UEDA S., Acta Metall. 20 (1972) 759.

[8] HOWE J.M., DAHMEN U., GRONSKY R., Phil. Mag. A 56 (1987) 31. 